University of Nebraska - Lincoln

DigitalCommons@University of Nebraska - Lincoln

Faculty Publications, Department of Child, Youth, and Family Studies

Psychological Distress Prevalence and Associated Stressors and Supports Among Urban-Displaced Congolese Adults in Kenya

Julie A. Tippens

Holly Hatton-Bowers

Ryan Honomichl

Lorey Wheeler

Helen M. Miamidian

See next page for additional authors

Follow this and additional works at: https://digitalcommons.unl.edu/famconfacpub

Part of the Developmental Psychology Commons, Family, Life Course, and Society Commons, Other Psychology Commons, and the Other Sociology Commons

This Article is brought to you for free and open access by the Child, Youth, and Family Studies, Department of at DigitalCommons@University of Nebraska - Lincoln. It has been accepted for inclusion in Faculty Publications, Department of Child, Youth, and Family Studies by an authorized administrator of DigitalCommons@University of Nebraska - Lincoln. 


\section{Authors}

Julie A. Tippens, Holly Hatton-Bowers, Ryan Honomichl, Lorey Wheeler, Helen M. Miamidian, Kirstie L.

Bash, Michelle C Howell Smith, Dulo Nyaoro, J. Joshua Byrd, Samuel E. Packard, and Nicolette I. TeufelShone 


\title{
Psychological Distress Prevalence and Associated Stressors and Supports Among Urban-Displaced Congolese Adults in Kenya
}

\author{
Julie A. Tippens, ${ }^{1}$ Holly Hatton-Bowers,${ }^{1}$ Ryan Honomichl, ${ }^{2}$ \\ Lorey A. Wheeler, ${ }^{3}$ Helen M. Miamidian, ${ }^{4}$ Kirstie L. Bash, ${ }^{5}$ \\ Michelle C. Howell Smith, ${ }^{6}$ Dulo Nyaoro, ${ }^{7}$ J. Joshua Byrd, ${ }^{1}$ \\ Samuel E. Packard, ${ }^{8}$ and Nicolette I. Teufel-Shone ${ }^{9}$
}

1 Department of Child, Youth \& Family Studies, University of Nebraska-Lincoln

2 Department of Quantitative Health Sciences, Lerner Research Institute,

Cleveland Clinic

3 Nebraska Center for Research on Children, Youth, Families and Schools,

University of Nebraska-Lincoln

4 Department of Social Transformation, Eastern University

5 Center for Public Partnerships \& Research, University of Kansas

6 Interprofessional Academy of Educators, University of Nebraska Medical Center

7 Department of Political Science, Peace Institute, Moi University

8 Asthma and Airway Disease Research Center, University of Arizona

9 Department of Health Sciences, Northern Arizona University
Correspondence - Julie A. Tippens, Department of Child, Youth \& Family Studies, University of Nebraska-Lincoln, 205 Louise Pound Hall, Lincoln, NE 68588, United States. Email:
jtippens@unl.edu

\section{ORCIDs}

Julie A. Tippens https://orcid.org/0000-0003-0465-3570

Holly Hatton-Bowers https://orcid.org/0000-0002-4165-791X

Ryan Honomichl https://orcid.org/0000-0002-0535-4268

Lorey A. Wheeler https://orcid.org/0000-0001-9975-6702

Kirstie L. Bash https://orcid.org/0000-0002-1425-5632

Michelle C. Howell Smith https://orcid.org/0000-0001-7397-4912

Samuel E. Packard https://orcid.org/0000-0001-8607-792X

Nicolette I. Teufel-Shone https://orcid.org/0000-0002-7548-819X

Published in American Journal of Orthopsychiatry, 2021 doi:10.1037/ort0000564

Copyright (C) 2021 Global Alliance for Behavioral Health and Social Justice; published by American Psychological Association. Used by permission.

Published July 22, 2021.

"This paper is not the copy of record and may not exactly replicate the authoritative document published in the APA journal." 


\begin{abstract}
Background: There is limited understanding of the prevalence of psychological distress and associated stressors and supports among displaced adults in low- and middleincome first asylum countries.

Method: This article reports the findings of a cross-sectional study. We recruited 245 Congolese adults (18-80 years) residing in Nairobi, Kenya using snowball sampling. Data were collected using an interviewer-administered questionnaire consisting of sociodemographic characteristics, the Self-Reporting Questionnaire (SRQ-20), and a locally developed stressors and supports survey. We used multivariable logistic regression to examine associations among sociodemographic, stressor, and support variables and the likelihood of experiencing psychological distress.

Results: More than half of the participants (52.8\%) reported symptoms indicative of psychological distress. Factors associated with increased psychological distress included perceiving to have a useful role in one's family or community, AOR = 1.85; $95 \% \mathrm{CI}[1.1 .17,3.11], p=.012$, feeling confused or not knowing what to do, AOR $=2.13 ; 95 \% \mathrm{CI}[1.20,4.6], p=.014$, and feeling afraid to leave home for medical/ health care to help with an illness, AOR $=1.57 ; 95 \%$ CI $[1.17,2.15], p<.01$. Additionally, ethnic Banyamulenge Congolese adults without legal refugee status had an increased likelihood of experiencing psychological distress, AOR $=.07 ; 95 \% \mathrm{CI}$ $[0, .74], p=.035$.

Conclusion: Future research is warranted to understand how to implement targeted mental health and psychosocial support (MHPSS) to improve urban-displaced adults' sense of safety and belonging. Our findings suggest that legal refugee status is an important structural determinant of mental health, which should be considered in MHPSS practice and policy.
\end{abstract}

Keywords: mental health and psychosocial support (MHPSS), refugees, asylum seekers, structural vulnerability, Kenya

Public Policy Relevance Statement: There is limited research examining how structural determinants are associated with urban-displaced adults' mental health in postmigration settings. Results from this study suggest that refugee status determination is a significant determinant of mental health status. One implication stemming from the results suggests that the prompt registration of urban refugees may be an essential component of comprehensive mental health and psychosocial support (MHPSS) in humanitarian settings.

At the end of 2019, nearly 80 million people were forcibly displaced from their homes due to conflict or persecution (United Nations Refugee Agency, 2020b). Of the approximately 26 million individuals who have refugee status, $85 \%$ are hosted in low- and middle-income countries (LMICs) and more than half live in cities (United Nations Refugee Agency, 2020b). Although many urban refugees move to cities to access employment, education, and health care, they often reside in 
informal squatter settlements and compete for scarce resources with other refugees, migrants, and host country nationals living in poverty (Amara \& Aljunid, 2014; 0’Loghlen \& McWilliams, 2017). Structural vulnerability provides a useful theoretical framework to capture this camp-to-urban demographic shift and examine the mental health of refugees residing in cities. Structural vulnerability theory draws on the social and structural determinants of health to demonstrate how "positionality imposes physical/emotional suffering on specific population groups and individuals in patterned ways" (Quesada et al., 2011, p. 340). This framing highlights how sociocultural, political, and historical contexts together with demographic attributes (e.g., sex/gender, citizenship status) and assumed status (e.g., assumed intelligence, "deservingness") create and exacerbate health inequities (Bourgois et al., 2017; Quesada et al., 2011).

Kenya is an important host country for refugees from Central, East, and the Horn of Africa subregions, with a population of more than 494,000 refugees (United Nations Refugee Agency, Kenya, 2020). The Government of Kenya (GOK) administers an encampment policy in which refugees are required to reside in one of the countries two larger integrated camp complexes or settlements (United Nations Refugee Agency, Kenya, 2020). However, this policy has only been arbitrarily enforced and individuals who meet the exemption criteria for not residing in camps (e.g., due to medical or protection needs) are permitted to reside in cities. More than 80,000 refugees were registered in Nairobi in August 2020 (Lambo, 2012; United Nations Refugee Agency, Kenya, 2020), but this is a conservative estimate since many urban refugees live in the capital city without legal documentation (Pavanello et al., 2010). Residing in Nairobi poses a number of threats to refugees' mental and psychosocial health. The urban spaces of Kenya have been described by the United Nations Refugee Agency (UNHCR) as "complex," "unpredictable," and "insecure" (United Nations Refugee Agency, Kenya, 2020). Although there is scarce literature on urban refugees' mental health, existing research in urban settings has documented the deleterious health effects of discrimination, harassment, and police extortion (Campbell, 2006; Grabska, 2006; Stark et al., 2015; Thomas et al., 2011); inadequate access to human services, health care, and education (Alexander, 2008; Briant, 2004); and poverty, food insecurity, and inadequate housing (Campbell, 2006; Grabska, 2006; O’Loghlen \& McWilliams, 2017). 
Such forms of structural and political violence have detrimental effects on the well-being of affected population groups (Farmer, 1996; Sousa, 2013). Research on political violence has shown that its targets exhibit increased mistrust, fear and suspicion, and social isolation and withdrawal (Sousa, 2013).

\section{Mental and Psychosocial Health of Displaced Congolese Adults in African Countries}

In recent decades, Congolese refugees have been forcibly displaced due to the first and second Congo Wars (1996-2003) and related regional instability (Turner, 2007). There were more than 918,000 refugees originating from the Democratic Republic of the Congo (DRC) as of February 2020 (United Nations Refugee Agency, 2020a). Most Congolese refugees seek asylum in neighboring Uganda, followed by Burundi, Tanzania, Rwanda, South Africa, Zambia, and Kenya (United Nations Refugee Agency, n.d.a). Congolese refugees have been shown to experience poor mental and psychosocial health in postmigration settings. Poor mental health is generally attributed to premigration trauma (e.g., family members murdered, loss of property, physical, and sexual violence), difficult transit (e.g., family separation, physical, and sexual violence), and daily stressors in postmigration settings (e.g., poverty, inadequate housing, experiences of xenophobia; Ainamani et al., 2020; Ingabire \& Richters, 2020; Smit \& Rugunanan, 2015; Ssenyonga et al., 2013). A 2013 study with 425 adult Congolese refugees in the Nakivale settlement in Uganda showed $61.7 \%$ of respondents met the criteria for posttraumatic stress disorder (PTSD; Ssenyonga et al., 2013); in a later study with the same population, 89\% met these same criteria (Ainamani et al., 2020). In a qualitative case study with 10 Congolese women in Yeoville, South Africa, all participants had experienced trauma during the war and described a loss of hope, panic attacks, and suicidal ideation (Nkomo, 2019).

Postmigration stressors include language barriers, xenophobia and threats to physical safety, and poor access to bridging (e.g., host country nationals) and linking (e.g., formal institutions) forms of social capital (Labys et al., 2017; Smit, 2015; Tippens, 2017, 2020b). In their work with urban Congolese and Zimbabwean refugees in South Africa, Labys et al. (2017) reported that many participants described feelings of powerlessness and worthlessness and exhibited passive suicidal ideation. 
Chiumento et al. (2020) identified poor social cohesion as well as experiences of discrimination and inequity among Congolese refugees residing in Rwanda and Uganda. In a critical review on the social determinants of refugees' mental health in postmigration contexts, Hynie (2018) noted that isolation and lack of social support had particularly deleterious effects on well-being.

In contrast, perceived support, or the cognitive appraisal of connections to other people (Cohen \& Wills, 1985), has been associated with refugees' positive mental and psychosocial health in postmigration settings (Araya et al., 2007; Muhwezi \& Sam, 2004; Renner et al., 2012; Schweitzer et al., 2006; Tippens, 2017, 2020a). For example, perceived support from one's religious community has been documented as an important coping resource to promote overall well-being (Tippens, 2017, 2020a). Another source of support is the feeling one is not alone and has a sense of purpose, such as contributing to one's family or community (Snyder et al., 2020), as Tippens (2020a) found in her research with Congolese families in urban Tanzania. It is also important to note that different ethnic groups from the same country of origin have varying conflict, transit, and postmigration experiences and sources of support (Tippens, 2020b). For example, ethnic minority Banyamulenge refugees from DRC have been shown to have strong in-group bonding networks in postmigration Uganda and Kenya (Lyytinen, 2017; Tippens, 2017). This high reliance on in-group networks may be, at least in part, due to past experiences of discrimination in DRC and in neighboring refugee camps (Tippens, 2017). Similarly, Amisi (2006) noted that Congolese refugees described mistrust (of institutions, foreigners, and other Congolese) as essential to their survival during the Congo Wars. Such lack of trust in resources must be considered when examining salient, trusted sources of support in postmigration setting.

\section{Context of the Present Study}

Kenya is an important country-of-residence for displaced persons in the region and hosted more than 512,000 registered refugees and asylum seekers as of February 2021 (United Nations Refugee Agency, Kenya, 2021). More than 80,000 displaced individuals reside in the capital city, Nairobi; however, this is likely a conservative estimate as many individuals from refugee-like situations reside in the city without legal 
documentation (United Nations Refugee Agency, n.d.b). "Refugee-like situations" is a descriptive, inclusive category that encompasses individuals fleeing conflict and persecution but who have not been granted legal refugee status (e.g., for reasons of fear of registration, lack of registration in urban centers, or other barriers; United Nations Refugee Agency, n.d.b). Our study included Congolese adults from refugee-like situations as well as those who were formally registered and had legal refugee status.

Importantly, research for this cross-sectional study was conducted during Operation Usalama [Security] Watch in Kenya in 2014, when the GOK issued a directive requiring refugees in cities to relocate to camps in response to terrorist incidents committed by al Shabab, a Somalia-based Islamist insurgent group with links to al Qaeda (BBC News, 2017). The GOK response, based largely on racial profiling, was particularly detrimental to Somali refugees residing in the Eastleigh section of Nairobi (locally nicknamed "Little Mogadishu"). However, refugees, asylum seekers, and migrants from multiple countries of origin were rendered structurally vulnerable during this time, and reported increased abuses from police, employers (especially for those employed in the informal sectors), and Kenyans (Tippens, 2017). Random arrests, the transformation of a national stadium to an immigration detention center, forcible relocation to refugee camps, and deportation occurred during Operation Usalama Watch. In one instance the police raided a Christian church service at a predominantly Congolese (majority ethnic Banyamulenge) place of worship, resulting in more than 200 Congolese refugees being sent to the Somali-majority Dadaab refugee camp complex (Tippens, 2017). In addition to promoting ethno-racial profiling in the police force, the GOK also encouraged Kenyan civilians to report refugees to the authorities, further fragmenting refugees' sense of security and access to social support and community resources (Tippens, 2017).

Given the context in which this research took place, the central aim of this study was to understand the prevalence of psychological distress among Congolese refugees during a period of structural vulnerability and political violence. Our secondary aim was to examine how sociodemographic characteristics and perceived stressors and supports related to psychological distress. 


\section{Method}

\section{Study Design and Site}

This article presents the quantitative findings from a sequential exploratory mixed-methods project, a design selected to enhance community health research (Andrew \& Halcomb, 2007).We selected a sequential [qualitative $\rightarrow$ quantitative] design to better understand the depth and breadth of urban refugees' psychosocial health as well as to inform quantitative data collection (Andrew \& Halcomb, 2007; Plano-Clark \& Ivankova, 2016). The first phase of this research consisted of ethnographic participant observation, in-depth interviews, and small group discussions and is reported elsewhere (Tippens, 2017, 2020b). Findings from Phase I informed the development of a survey to inventory Congolese refugees' sources of stress and support, which was one of the instruments used to collect the data presented in this article. The first author conducted fieldwork in Nairobi over 12 months in 2012 and 2014; the presented cross-sectional data were collected between May and August 2014.

\section{Study Procedures and Selection of Participants}

The principal investigator (PI) recruited five Congolese research assistants (RAs) through nongovernmental organizations (NGOs); two of the RAs were women. RAs participated in a two-day training facilitated by the PI that covered research ethics, informed consent, and data collection procedures. The PI and RAs collected data in six neighborhoods with high proportions of Congolese residents. Ethnic Banyamulenge Congolese adults primarily resided in three periurban neighborhoods. We oversampled ethnic Banyamulenge participants in these neighborhoods to explore possible differences in mental health based on literature and fieldwork observations related to this ethnic minority group's experiences of discrimination in premigration DRC as well as preferred in-group sources of support and different coping strategies (Lyytinen, 2017; Tippens, 2017). Participants were recruited using purposive and snowball sampling until 25 households in each neighborhood were reached (household $N=150$ ). We first met with community and religious leaders at local institutions (e.g., community centers, churches) 
to describe the purpose of the study, seek permission to work in neighborhoods, and ask for leaders to help recruit participants. We asked potential interviewees where they wanted to participate; most interviews took place in people's homes. In three instances, participants in the same neighborhood were concerned about neighbors overhearing conversations and learning they were from the DRC. In these cases, interviews took place at a Congolese-majority church with the permission of the pastor. All household members who fled the DRC due to conflict or persecution, were at least 18-years old, and fluent in Kiswahili were eligible to participate in the study. The Institutional Review Board (IRB) at the University of Arizona (Protocol \#: 1300000726) and the Kenyan National Commission for Science, Technology, and Innovation (NACOSTI) approved the study protocol. Participants were consented by the first author (with the assistance of an interpreter) and provided a signature. To address high levels of preliteracy in the target population, the informed consent form was read aloud and participants were asked if they had any questions after each subsection of the form. Participants were provided a copy of the informed consent form in Kiswahili as well as a list of resources (e.g., psychosocial programs, food assistance programs) for refugees residing in Nairobi.

\section{Measures}

We used sociodemographic data and measures of Congolese refugees' psychological distress and perceived stressors and supports in our analyses. These measures were interviewer-administered by the PI and Congolese RAs. The sociodemographic questionnaire and stressors and supports survey were translated and back-translated in an iterative process by the PI and RAs during three meetings, each lasting between 2 and 3.5 $\mathrm{hr}$. We also made slight adjustments to the Kiswahili version of the Self Reporting Questionnaire (SRQ-20) during these meetings to better reflect the language as spoken by Congolese participants. Collaborative, iterative translation processes have been recommended to deal with challenges that arise in cross-cultural survey research (e.g., losing original meaning from source material, assumptions of equivalence in direct translations; Douglas \& Craig, 2007; Su \& Parham, 2002). Indeed, it took several hours to modify questions on the SRQ-20 to capture meaningful differences in "poor digestion" (question 7) and "uncomfortable feelings in [one's] stomach" (question 19) in Kiswahili (Beusenberg \& Orley, 
1994). As part of the iterative process, we also piloted questionnaires with 30 Congolese men and women representing six ethnic groups (Banyamulenge $n=10$ ), making final adjustments during the last research meeting to finalize the translation of the survey instrument. All questionnaires were conducted in Kiswahili by an RA with the PI present.

\section{Outcome Variable.}

\section{Psychological Distress}

The Self Reporting Questionnaire (SRQ-20), a dichotomous response survey developed for use in LMICs (Beusenberg \& Orley, 1994), was used to assess psychological distress. The survey includes a set of 20 somatic and psychological symptoms indicative of anxiety and depression over the past 30 days (Cronbach $\alpha=.82$ in the current sample). Each of the items is scored 0 (absence of symptom) or 1 (presence of symptom). The Kiswahili version of the SRQ-20 has demonstrated good internal consistency with Congolese adults experiencing chronic conflict (Snyder et al., 2020; $\alpha=0.82$ ) and with a sample of Congolese women in Rwanda (Sipsma et al., 2015; $\alpha=0.91$ ). Additionally, in a systematic review of tools that have been validated in multiple settings, Ali et al. (2016) broadly recommended using the SRQ-20 to screen for common mental disorders. In our study, we used Sipsma et al.'s (2015) established cut-off score of 10: scores greater than 10 indicated psychological distress; scores lower than 10 indicated that participants were not experiencing psychological distress.

\section{Contextual Variables.}

\section{Sociodemographic Characteristics}

Data for all household members were collected using a household inventory. Household members and roles (e.g., head-of-household, dependents) and corresponding information were collected in a grid format, including age, sex, marital status, length of time in Nairobi, employment status, educational attainment, ethnicity, and refugee status (Table 1).

\section{Psychosocial Stressors and Supports}

A locally constructed stressors and supports survey was developed with Congolese RAs based on literature reviews and Phase I research with the study population. This five-item survey consisted of questions 
Table 1 Participant Characteristics

\begin{tabular}{lrr} 
Characteristics & $M(S D)$ or $\%$ & Range or frequencies \\
\hline Age & $31.59(12.29)$ & $18-80$ \\
Years in Nairobi & $3.93(3.44)$ & $.16-19$ \\
Highest level of education & $4.41(2.08)$ & $1-7$ \\
Male & $49.40 \%$ & 120 \\
Has dependents & $64.30 \%$ & 155 \\
Legal refugee status & $75.50 \%$ & 163 \\
Banyamulenge & $48.30 \%$ & 113 \\
Marital status: married & $56.60 \%$ & 128 \\
Average number of children & $2.08(2.44)$ & $0-10$ \\
\hline
\end{tabular}

$N=245 . M=$ mean; $S D=$ standard deviation.

on: (a) perceived access to religious supports during distress, (b) feeling of use to family or community, (c) feeling safe to leave the home to access medical supports when experiencing illness, (d) feeling in an unfamiliar situation and not knowing what to do, and (e) feeling isolated or alone. Question D was taken from Antonovsky's (1993) sense of coherence (SOC-13) scale, as Congolese RAs felt it best reflected refugees' experiences with Operation Usalama [Security] Watch. Respondents were asked to indicate their experiences with each item in the past 30 days; responses were coded on a 5 -point scale ranging from " 1 " (never) to "5" (always). We used the individual items in our analyses instead of a summed score to have a more nuanced understanding of potential sources of stressors and perceived supports.

\section{Statistical Analyses}

We ran descriptive analyses to test for assumptions of normality and to identify outliers and missing data using R (R Core Team, 2020). Missingness for the study variables ranged $0 \%-11.84 \%$; with refugee status missing for $11.84 \%(n=29)$, marital status missing for $7.77 \%(n=19)$, and the item "work suffering" from the SRQ-20 measure having 9.39\% $(n=23)$ missing responses. After examining descriptive statistics and correlations between all of the study variables, we utilized odds ratio and $95 \%$ confidence intervals to estimate the association between predictors and psychological distress. Psychological distress was examined 
by the inclusion or exclusion of each predictor using univariate and multivariable analyses. First, univariate analysis was conducted to estimate the unadjusted odd ratios (ORs) with 95\% confidence intervals to examine the association of each variable with psychological distress (SRQ-20 $>10$ ). In the analysis of the unadjusted ORs, we examined the independent association of each of our contextual variables with psychological distress. We then conducted multivariable logistic regression; using $p<$ .05 to indicate statistical significance that produced adjusted ORs (which are adjusted given the other variables in the model). All analyses were conducted using R (R Core Team, 2020).

\section{Results}

\section{Descriptive Statistics}

Percentages, frequencies, means, and standard deviations of the study variables are reported in Tables 1 and 2. The average age of participants was 31.59 years ( $S D=12.29), 49.4 \%(n=120)$ identified as male and $56.6 \%(n=128)$ indicated they were married. More than half of participants reported having legal refugee status $(75.5 \%, n=163)$. The average number of years in Nairobi was 3.93 years $(S D=3.88)$. Almost half of the participants identified as ethnic Banyamulenge $(48.3 \%, n=113)$.

\section{Displaced Congolese Adults' Psychological Distress}

As shown in Table 2, symptoms of psychological distress were high, with $52.8 \%$ reporting scores considered to be indicative of psychological distress (SRQ-20 > 10). The mean of the SRQ-20 was 10.93 (SD = 4.34 ) ranging $0-18$. Percentages and frequencies for the individual scale items are reported in Table 2.

\section{Univariate Analyses-Unadjusted Results}

The univariate and multivariable results are shown in Table 3 (Model 1). In the univariate model, among the sociodemographic factors, being older in age and having dependents were associated with a higher likelihood of experiencing psychological distress, whereas being male and having legal refugee status were associated with a lower likelihood of 
Table 2 Descriptive Statistics

\begin{tabular}{lrr} 
Variables & $\begin{array}{r}\text { M (SD) } \\
\text { or } \%\end{array}$ & $\begin{array}{r}\text { Range or } \\
\text { frequencies }\end{array}$ \\
& & \\
\hline SRQ-20 & $57.7 \%$ & 142 \\
Headaches often & $47.2 \%$ & 116 \\
Poor appetite & $61.0 \%$ & 150 \\
Sleep badly & $57.7 \%$ & 142 \\
Easily frightened & $24.8 \%$ & 60 \\
Hand shake & $74.3 \%$ & 182 \\
Feeling nervous, tense, worried & $59.3 \%$ & 144 \\
Poor digestion & $86.6 \%$ & 206 \\
Trouble thinking & $75.0 \%$ & 183 \\
Feeling unhappy & $75.5 \%$ & 185 \\
Cry more than usual & $77.0 \%$ & 187 \\
Difficult to enjoy activities & $64.4 \%$ & 143 \\
Work is suffering & $27.2 \%$ & 66 \\
Feeling unable to play a useful part & $35.5 \%$ & 86 \\
Lost interest & $47.3 \%$ & 115 \\
Feel tired all the time & $50.6 \%$ & 124 \\
Experience uncomfortable feelings & $51.0 \%$ & 125 \\
Easily tired & $31.7 \%$ & 77 \\
Feeling like a worthless person & $9.8 \%$ & 24 \\
Thoughts of ending life & & $1-5$ \\
Psychosocial supports and stressors & $3.56(1.57)$ & $1-5$ \\
Can ask for help from religious community during difficult times & $4.69(0.09)$ & $1-5$ \\
Have a useful role to play in family and/or community & $3.09(1.82)$ & $1-5$ \\
Feel isolated or alone in Nairobi & $4.61(1.59)$ & $3.53(1.59)$ \\
Confused or do not know what to do & & \\
Avoided seeking health care or medical treatment for an illness & & \\
$\quad$ because afraid to leave home & & \\
& & \\
& &
\end{tabular}

$N=245 . M=$ mean; $S D=$ standard deviation; SRQ-20 = symptoms of psychological distress.

experiencing psychological distress. Among the stressors, feeling isolated or alone, confused or not knowing what to do, and being afraid to seek health/medical care when having an illness were associated with a higher likelihood of experiencing psychological distress. Among the supports, access to religious supports was associated with a lower likelihood of experiencing psychological distress whereas perceptions of having a useful role in the family/community were associated with a higher likelihood for experiencing psychological distress. 
Table 3 Results From Models Examining Displaced Congolese Adults' Stressors and Supports Related to Psychological Distress

\begin{tabular}{|c|c|c|c|c|c|c|}
\hline \multirow[b]{2}{*}{ Contextual variables } & \multicolumn{3}{|c|}{ Model 1: unadjusted } & \multicolumn{3}{|c|}{ Model 2: adjusted } \\
\hline & $\begin{array}{c}\text { Unadjusted } \\
\text { odds ratio }\end{array}$ & $95 \% C I$ & $p$ value & $\begin{array}{l}\text { Adjusted } \\
\text { odds ratio }\end{array}$ & $95 \% C I$ & $p$ value \\
\hline \multicolumn{7}{|l|}{ Sociodemographics } \\
\hline Male & .48 & $.28, .82$ & $<.01$ & .89 & $.36,2.17$ & .795 \\
\hline Age & 1.03 & $1.00,1.05$ & .024 & 1.04 & $1.00,1.08$ & .056 \\
\hline Married & .62 & $.35,1.08$ & .094 & .31 & $.10, .84$ & .025 \\
\hline Has dependents & 2.55 & $1.46,4.49$ & $<.01$ & 2.67 & $.96,7.77$ & .063 \\
\hline Banyamulenge & .70 & $.41,1.21$ & .205 & 11.38 & $1.19,145.33$ & .045 \\
\hline Legal refugee status & .38 & $.18, .77$ & $<.01$ & 1.52 & $.34,6.68$ & .574 \\
\hline \multicolumn{7}{|l|}{ Stressors and supports } \\
\hline Feeling isolated or alone & 1.57 & $1.34,1.84$ & $<.01$ & 1.32 & $.99,1.75$ & .054 \\
\hline Confused or do not know what to do & 2.47 & $1.70,3.81$ & $<.01$ & 2.13 & $1.20,4.06$ & .014 \\
\hline Avoid seeking medical/health care & 2.09 & $1.70,2.60$ & $<.01$ & 1.57 & $1.17,2.15$ & $<.01$ \\
\hline Access religious supports when distressed & .70 & $.58, .83$ & $<.01$ & .75 & $.53,1.05$ & .101 \\
\hline Have a useful role in family/community & 1.64 & $1.21,2.34$ & $<.01$ & 1.85 & $1.17,3.11$ & .012 \\
\hline Banyamulenge $\times$ Legal refugee status & - & - & - & .07 & $.00, .74$ & .035 \\
\hline
\end{tabular}

$N=245 . \mathrm{CI}=$ confidence interval.

\section{Multivariable Analyses-Adjusted Results}

The adjusted multivariable results are shown in Table 3 (Model 2). In Model 2, among the sociodemographic factors, among ethnic Banyamulenge adults, those with legal refugee status were at decreased odds compared to those lacking legal refugee status for experiencing psychological distress. Among the stressors, displaced Congolese adults who indicated higher levels of feeling afraid to leave the home for medical/ health care when having an illness were at an increased likelihood for experiencing psychological distress as were those who more often felt confused or did not know what to do. Among the supports, seeking religious supports when distressed and being married were significantly associated with a lower likelihood of psychological distress. However, Congolese adults who reported higher perceptions of being useful to family or community were at an increased likelihood of experiencing psychological distress (Figure 1). 


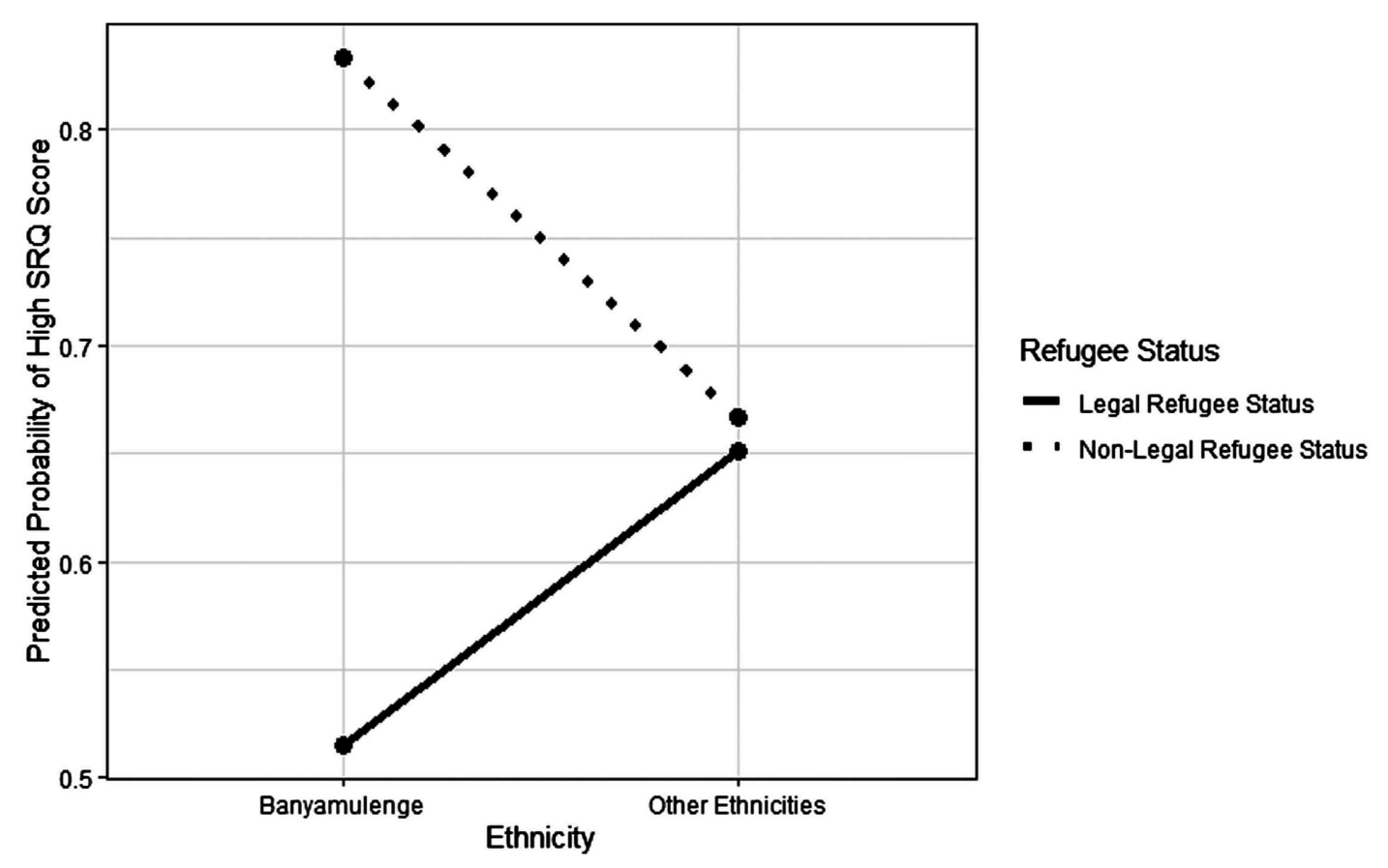

Figure 1 Interaction Between Identifying as Banyamulenge and Having Legal Refugee Status for the Likelihood of Experiencing Psychological Distress

\section{Discussion}

Our findings highlight the high prevalence of psychological distress among Congolese refugees in an LMIC setting during a period of structural vulnerability. More than half of the sample (52.8\%) who completed the SRQ-20 were experiencing psychological distress at the time of this research. These results are consistent with Misghinna et al.'s (2020) findings with a predominantly Congolese sample $(n=242 / 374 ; 64 / 71 \%)$ of urban refugees attending a refugee center in Kampala, Uganda; the authors found that $51 \%(n=191)$ of the overall sample endorsed symptoms indicative of psychological distress, although it should be noted that a cut-off score of 6 was used in the Misghinna et al. (2020) study versus a cutoff of point of 10 used in our study. Our findings also elucidate important stressors and supports that serve as determinants of mental health. For example, feeling afraid to leave home to access needed medical supports when having an illness as well as not knowing what to do in a new postmigration situation increased the odds of experiencing 
psychological distress. It is plausible that feeling afraid to leave home was a direct result of Operation Usalama Watch and related environmental threats to well-being (i.e., "fear of leaving home" as a proxy for fear of deportation or forced relocation to a refugee camp). Nairobi has long been documented as an inhospitable residence for refugees from neighboring countries. Prior to Operation Usalama Watch, documented threats to local integration included police harassment and occasional raids in neighborhoods with large migrant populations, poor access to formal livelihood opportunities, lack of availability of and access to health and social services, community violence, and xenophobia and social discrimination (Campbell, 2006; Im et al., 2017; Mutiso et al., 2019; Nyaoro, 2010; Pavanello et al., 2010). The GOK's Operation Usalama Watch added an additional layer of insecurity, characterized by widespread human rights abuses against refugees, including arbitrary arrests, forcible relocation, and deportation (Tippens, 2017), the latter which violates the principle of nonrefoulement in international law (Nyaoro, 2019). Taken together, these factors provide greater context for the pervasive fear and confusion reported by Congolese participants while simultaneously supporting previous findings that political violence has a harmful effect on mental health and overall well-being (Pedersen, 2002; Tol et al., 2010; Valdez et al., 2015).

We hypothesized that older adults, participants living in a household with dependents, and ethnic Banyamulenge Congolese refugees would be at increased risk for psychological distress compared with their counterparts in the sample. While age and living with dependents were statistically significant predictors of psychological distress in the univariate analysis, the $\mathrm{p}$ values in the fully adjusted model did not meet the selected threshold to conclude statistical significance ( $p=.056$ and .063 , respectively). In a scoping review, older refugees were found to report poorer psychosocial health and have more common mental disorders compared with their younger counterparts (Virgincar et al., 2016). Three possible reasons for these contrasting findings include (a) a relatively small sample of older adults in our study, (b) the time during which this study was conducted, specifically the possibility of state-sanctioned political violence resulting in increased endorsement of psychological distress symptoms among all participants in the sample, and (c) the identified supports and stressors partially account for the higher risk of adverse psychological outcomes among older adults 
reported elsewhere. Identifying as ethnic Banyamulenge was significantly associated with an increased likelihood of experiencing psychological distress, which may be explained by premigration and transit experiences of trauma and discrimination or by lack of overall integration into Nairobi (Tippens, 2017). Additionally, in May 2014 (during Operation Usalama [Security] Watch), police raided a Christian church, arresting 150 Banyamulenge refugees during Sunday worship and forcibly relocating them to a Somali-majority refugee camp (Dean, 2014; Tippens, 2017). This recent trauma may have resulted in higher likelihood of psychological distress. It is noteworthy that ethnic Banyamulenge participants with legal refugee status had decreased odds for psychological distress compared with those without legal refugee status, which may also be explained by the May 2014 church raids and a sense that legal status granted extra protection (although it should be noted that many among the arrested had legal refugee status). Although not statistically significant in the multivariable regression analysis, this same trend was observed for other ethnicities in the univariate model, suggesting the importance of refugee registration as a critical sociostructural determinant of mental health.

We also hypothesized that perceived support from religious networks and feeling useful to one's family and community would be associated with a decreased risk for psychological distress. After fully adjusting for other supports and stressors, religious support was not a significant independent predictor in our study $(p=.101)$ despite being a meaningful source of support identified by Congolese refugees during the qualitative phase of this study (Tippens, 2017). This may be explained by relatively small sample size, the need for additional clarification in our survey regarding the type of support provided within religious networks (e.g., spiritual, emotional, instrumental), or because inclusion as a continuous variable may not be the most appropriate way to measure or model religious support in this context. We were surprised that feeling useful to one's family or community more often increased the likelihood of experiencing psychological distress. While feeling of use has shown to be important for supporting mental health in previous studies with Congolese refugees (e.g., Ingabire \& Richters, 2020), it is possible that participants in our study felt burdened providing emotional, instrumental, informational, or appraisal support in such a structurally vulnerable context (Omata, 2012). As such, the provision of support via 
humanitarian organizations is critical to ensuring refugees are not overwhelmed by demands to support family and community members. The sequential exploratory mixed methods design qualitatively identified potential predictors of psychological distress for subsequent quantitative analysis; some of these qualitative findings were supported by the results of the fully adjusted model, while others were not. Future mixedmethods studies could explore comparative societal contexts for refugee mental health, thus providing more nuanced understandings of how stressors and supports differentially relate to psychological distress, and in what contexts (Bannister-Tyrrell \& Meiqari, 2020).

\section{Limitations}

Findings must be interpreted in light of several limitations to this study. The PI's outsider status as a white American woman may have influenced social desirability bias or other responses by participants. Similarly, participants and Congolese RA interviewers were not matched by sex, ethnicity, or other characteristics due to limited resources, which may have also influenced responses. Although snowball sampling is considered acceptable in settings with difficult- to-reach populations, this recruitment strategy - in tandem with a relatively small sample size-limits our ability to generalize findings to Congolese refugees more broadly. Additionally, the cross-sectional design prohibits causal inference. The use of longitudinal designs will be important to glean additional insight into the relationships among structural vulnerability and psychological distress indicators. Our analyses did not include other forms of psychosocial resources and support that may be associated with decreasing psychological distress (e.g., socioeconomic status, having a trusting person to talk with when feeling distressed, a sense of hope). Future research may benefit from identifying if these additional psychosocial resources and supports are importantly related to psychological distress.

\section{Conclusion and Broader Implications}

Our findings have important implications for mental health and psychosocial support (MHPSS) for urban refugees. De Jong et al. (2015) argued for a public health approach to address the mental health of youth 
affected by political violence and humanitarian emergencies. Similarly, in its Global Strategy for Public Health report, UNHCR highlighted the importance of integrating MHPSS into the health, protection, and education sectors (United Nations Refugee Agency, 2014). Such strategies recognize the social and structural determinants of mental health. For example, our study revealed a strong association between refugee status determination and mental health; therefore, prompt refugee registration in urban centers should be part of a comprehensive MHPSS package. Dickson and Bangpan (2018) have similarly asserted that MHPSS should be responsive to political and sociocultural contexts to ensure they are appealing to target populations. Addressing the social and structural determinants of health require a systems-oriented, Health in All Policies (HiAP) approach (Centers for Disease Control \& Prevention, n.d.), which is critical for successful humanitarian interventions.

Disclosures We have no known conflict of interest to disclose.

Acknowledgments We thank the Congolese women and men who participated in this study. We are also grateful to Anne, Patrick, Rinado, Alex, and Mohamed for their invaluable contributions during fieldwork. Many thanks to Drs. Burris (Duke) Duncan, Mark Nichter, and Ivy Pike for insightful conversations and feedback at each stage of JAT's dissertation project as well as to the anonymous reviewers whose thorough and thoughtful engagement with the manuscript strengthened the final version.

\section{References}

Ainamani, H. E., Elbert, T., Olema, D. K., \& Hecker, T. (2020). Gender differences in response to war-related trauma and posttraumatic stress disorder-A study among the Congolese refugees in Uganda. BMC Psychiatry, 20(1), Article 17. https://doi.org/10.1186/s12888-019-2420-0

Alexander, A. (2008). Without refuge: Chin refugees in India and Malaysia. Forced Migration Review, 30, 36-37.

Ali, G. C., Ryan, G., \& De Silva, M. J. (2016). Validated screening tools for common mental disorders in low and middle income countries: a systematic review. PloS one, 11(6), Article e0156939. https://doi.org/10.1371/journal.pone.0156939

Amara, A. H., \& Aljunid, S. M. (2014). Noncommunicable diseases among urban refugees and asylum-seekers in developing countries: A neglected health care need. Globalization and Health, 10(1), Article 24. https://doi. org/10.1186/1744-8603-10-24 
Amisi, B. (2006). An exploration of the livelihood strategies of Durban Congolese refugees. A report for the United Nations Refugee Agency. UNHCR.

Andrew, S., \& Halcomb, E. J. (2007). Mixed methods research is an effective method of enquiry for community health research. Contemporary Nurse, 23(2), 145-153. https://doi.org/10.5172/conu.2006.23.2.145

Antonovsky, A. (1993). The structure and properties of the sense of coherence scale. Social Science \& Medicine, 36(6), 725-733. https://doi. org/10.1016/0277-9536(93)90033-Z

Araya, M., Chotai, J., Komproe, I. H., \& de Jong, J. T. V. M. (2007). Gender differences in traumatic life events, coping strategies, perceived social support and sociodemographics among postconflict displaced persons in Ethiopia. Social Psychiatry and Psychiatric Epidemiology, 42(4), 307-315. https://doi. org/10.1007/s00127-007-0166-3

Bannister-Tyrrell, M., \& Meiqari, L. (2020). Qualitative research in epidemiology: Theoretical and methodological perspectives. Annals of Epidemiology, 49, 27-35. https://doi.org/10.1016/j.annepidem.2020.07.008

BBC News. (2017). Who are al-Shabab? Retrieved December 22, 2017, from https:// www.bbc.com/news/world-africa-15336689

Beusenberg, M., \& Orley, J. (1994). A user's guide to the Self-Reporting Questionnaire (SRQ). World Health Organisation.

Bourgois, P., Holmes, S. M., Sue, K., \& Quesada, J. (2017). Structural vulnerability: Operationalizing the concept to address health disparities in clinical care. Academic Medicine, 92(3), 299-307. https://doi.org/10.1097/ ACM.0000000000001294

Briant, N. (2004). An investigation of the perceived needs and priorities held by African Refugees in an urban setting in a first country of Asylum. Journal of Refugee Studies, 17(4), 437-459. https://doi.org/10.1093/jrs/17.4.437

Campbell, E. H. (2006). Urban refugees in Nairobi: Problems of protection, mechanisms of survival, and possibilities for integration. Journal of Refugee Studies, 19(3), 396-413. https://doi.org/10.1093/jrs/fel011 Centers for Disease Control and Prevention. (n.d.). Health in all policies. https://www.cdc.gov/policy/ hiap/index.html

Chiumento, A., Rutayisire, T., Sarabwe, E., Hasan, M. T., Kasujja, R., Nabirinde, R., Mugarura, J., Kagabo, D. M., Bangirana, P., Jansen, S. \& Ventevogel, P. (2020). Exploring the mental health and psychosocial problems of Congolese refugees living in refugee settings in Rwanda and Uganda: A rapid qualitative study. Conflict and Health, 14(1), Article 77. https://doi.org/10.1186/ s13031-020-00323-8

Cohen, S., \& Wills, T. A. (1985). Stress, social support, and the buffering hypothesis. Psychological Bulletin, 98(2), 310-357. https://doi. org/10.1037/0033-2909.98.2.310

de Jong, J. T., Berckmoes, L. H., Kohrt, B. A., Song, S. J., Tol, W. A., \& Reis, R. (2015). A public health approach to address the mental health burden of youth in situations of political violence and humanitarian emergencies. Current Psychiatry Reports, 17(7), Article 60. https://doi.org/10.1007/s11920-015-0590-0 
Dean, J. (2014). Collateral damage: Kenya's crackdown on terrorist attacks is catching refugees from other war-torn countries in its dragnet. World Magazine. https://world.wng.org/2014/06/collateral_damage

Dickson, K., \& Bangpan, M. (2018). What are the barriers to, and facilitators of, implementing and receiving MHPSS programmes delivered to populations affected by humanitarian emergencies? A qualitative evidence synthesis. Global Mental Health (Cambridge, England), 5, Article e21. https://doi.org/10.1017/ gmh.2018.12

Douglas, S. P., \& Craig, C. S. (2007). Collaborative and iterative translation: An alternative approach to back translation. Journal of International Marketing, 15(1), 30-43. https://doi.org/10.1509/jimk.15.1.030

Farmer, P. (1996). On suffering and structural violence: A view from below. Daedalus, 125(2), 261-283.

Grabska, K. (2006). Marginalization in Urban Spaces of the Global South: Urban Refugees in Cairo. Journal of Refugee Studies, 19(3), 287-307. https://doi. org/10.1093/jrs/fel014

Hynie, M. (2018). The social determinants of refugee mental health in the postmigration context: A critical review. Canadian Journal of Psychiatry, 63(5), 297303. https://doi.org/10.1177/0706743717746666

Im, H., Ferguson, A. B., Warsame, A. H., \& Isse, M. M. (2017). Mental health risks and stressors faced by urban refugees: Perceived impacts of war and community adversities among Somali refugees in Nairobi. The International Journal of Social Psychiatry, 63(8), 686-693. https://doi.org/10.1177/0020764017728966

Ingabire, C. M., \& Richters, A. (2020). Suicidal ideation and behavior among Congolese Refugees in Rwanda: Contributing factors, consequences, and support mechanisms in the context of culture. Frontiers in Psychiatry, 11, Article 299. https://doi.org/10.3389/fpsyt.2020.00299

Labys, C. A., Dreyer, C., \& Burns, J. K. (2017). At zero and turning in circles: Refugee experiences and coping in Durban, South Africa. Transcultural Psychiatry, 54(56), 696-714. https://doi.org/10.1177/1363461517705570

Lambo, I. (2012). In the shelter of each other: Notions of home and belonging amongst Somali refugees in Nairobi (The UN Refugee Agency Policy Development and Evaluation Services Unit, Research Paper No. 233). http://www.unhcr. org/4face3d09.pdf

Lyytinen, E. (2017). Informal places of protection: Congolese refugees' 'communities of trust' in Kampala, Uganda. Journal of Ethnic and Migration Studies, 43(6), 9911008. https://doi.org/10.1080/1369183X.2016.1207506

Misghinna, T. K., Nakimuli-Mpungu, E., Abbo, C., Kinyanda, E., Fellowship, T., \& Misghinna, T. K. (2020). Major depressive disorder and associated factors among adult refugees attending a refugee center in Kampala, Uganda. African Journal of Traumatic Stress, 5(1), 1-21.

Muhwezi, W., \& Sam, D. L. (2004). Adaptation of urban refugees in Uganda: A study of their socio-cultural and psychological well being in Kampala City. Journal of Psychology in Africa, 14(1), 37-46. https://doi.org/10.4314/jpa.v14i1.30608 
Mutiso, V., Warsame, A. H., Bosire, E., Musyimi, C., Musau, A., Isse, M. M., \& Ndetei, D. M. (2019). Intrigues of Accessing Mental Health Services Among Urban Refugees Living in Kenya: The Case of Somali Refugees Living in Eastleigh, Nairobi. Journal of Immigrant \& Refugee Studies, 17(2), 204-221. https://doi.org/10.1080/15562 948.2018.1433904

Nkomo, T. S. (2019). Exploring Congolese refugees and asylum seekers' survival strategies in South Africa: Implication for social work practice. Journal of Human Behavior in the Social Environment, 29(4), 499-518. https://doi.org/10.1080/109 11359.2018.1556142

Nyaoro, D. (2010). Policing with prejudice: How policing exacerbates poverty among urban refugees. International Journal of Human Rights, 14(1), 126-145. https:// doi.org/10.1080/13642980902933753

Nyaoro, D. (2019). From co-option, coercion to refoulement: Why the repatriation of refugees from Kenyan refugee camps is neither voluntary nor dignified. Refugees and forced migration in the horn and Eastern Africa (pp. 221-239). Springer. https://doi.org/10.1007/978-3-030-03721-5 12

O'Loghlen, A., \& McWilliams, C. (2017). The nexus of displacement, asset vulnerability and the Right to the City: The case of the refugees and urban poor of Dar es Salaam, Tanzania. International Journal of Urban Sustainable Development, 9(1), 21-45. https://doi.org/10.1080/19463138.2016.1254088

Omata, N. (2012). 'Community resilience or shared destitution?' Refugees' internal assistance in a deteriorating economic environment. Community Development Journal: An International Forum, 48(2), 264-279. https://doi.org/10.1093/cdj/ $\underline{\mathrm{bss} 057}$

Pavanello, S., Elhawary, S., \& Pantuliano, S. (2010). Hidden and exposed: Urban refugees in Nairobi, Kenya [Working Paper]. Overseas Development Institute.

Pedersen, D. (2002). Political violence, ethnic conflict, and contemporary wars: broad implications for health and social well-being. Social science\& medicine, 55(2), 175-190.

Plano-Clark, V., \& Ivankova, N. (2016). Why a guide to the field of mixed methods research?: Introducing a conceptual framework of the field. In V. Plano-Clark \& N. Ivankova (Eds.), Mixed methods research: A guide to the field (pp. 3-30).

Quesada, J., Hart, L. K., \& Bourgois, P. (2011). Structural vulnerability and health: Latino migrant laborers in the United States. Medical Anthropology, 30(4), 339362. https://doi.org/10.1080/01459740.2011.576725

R Core Team. (2020). R: A language and environment for statistical computing. $\mathrm{R}$ Foundation for Statistical Computing. https://www.R-project.org/

Renner, W., Laireiter, A.-R., \& Maier, M. J. (2012). Social support from sponsorships as a moderator of acculturative stress: Predictors of effects on refugees and asylum seekers. Social Behavior and Personality, 40(1), 129-146. https://doi. org/10.2224/sbp.2012.40.1.129

Schweitzer, R., Melville, F., Steel, Z., \& Lacherez, P. (2006). Trauma, postmigration living difficulties, and social support as predictors of psychological adjustment in resettled Sudanese refugees. The Australian and New Zealand Journal of Psychiatry, 40(2), 179-187. https://doi.org/10.1080/j.1440-1614.2006.01766.x 
Sipsma, H. L., Falb, K. L., Willie, T., Bradley, E. H., Bienkowski, L., Meerdink, N., \& Gupta, J. (2015). Violence against Congolese refugee women in Rwanda and mental health: A cross-sectional study using latent class analysis. BMJ Open, 5(4), e006299-e006299. https://doi.org/10.1136/bmjopen-2014-006299

Smit, R. (2015). "Trying to Make South Africa My Home”: Integration into the Host Society and the Well-being of Refugee Families. Journal of Comparative Family Studies, 46(1), 39-55. https://doi.org/10.3138/jcfs.46.1.39

Smit, R., \& Rugunanan, P. (2015). Transnational forced migration and negotiating emotional well-being: The case of women refugees in South Africa. Social Dynamics, 41(1), 184-203. https://doi.org/10.1080/02533952.2015.1029749

Snyder, J. D., Boan, D., Aten, J. D., Davis, E. B., Van Grinsven, L., Liu, T., \& Worthington, E. L., Jr. (2020). Resource loss and stress outcomes in a setting of chronic conflict: The conservation of resources theory in the Eastern Congo. Journal of Traumatic Stress, 33(3), 227-237. https://doi.org/10.1002/jts.22448

Sousa, C. A. (2013). Political violence, collective functioning and health: A review of the literature. Medicine, Conflict, and Survival, 29(3), 169-197. https://doi.org/10. $\underline{1080 / 13623699.2013 .813109}$

Ssenyonga, J., Owens, V., \& Olema, D. K. (2013). Posttraumatic growth, resilience, and posttraumatic stress disorder (PTSD) among refugees. Procedia: Social and Behavioral Sciences, 82, 144-148. https://doi.org/10.1016/j.sbspro.2013.06.238

Stark, L., DeCormier Plosky, W., Horn, R., \& Canavera, M. (2015). 'He always thinks he is nothing': The psychosocial impact of discrimination on adolescent refugees in urban Uganda. Social Science \& Medicine, 146, 173-181. https://doi. org/10.1016/j.socscimed.2015.10.045

$\mathrm{Su}, \mathrm{C}$. T., \& Parham, L. D. (2002). Generating a valid questionnaire translation for cross-cultural use. The American Journal of Occupational Therapy, 56(5), 581-585. https://doi.org/10.5014/ajot.56.5.581

Thomas, F. C., Roberts, B., Luitel, N. P., Upadhaya, N., \& Tol, W. A. (2011). Resilience of refugees displaced in the developing world: A qualitative analysis of strengths and struggles of urban refugees in Nepal. Conflict and Health, 5(1), Article 20. https://doi.org/10.1186/1752-1505-5-20

Tippens, J. A. (2017). Urban Congolese refugees in Kenya: The contingencies of coping and resilience in a context marked by structural vulnerability. Qualitative Health Research, 27(7), 1090-1103. https://doi. org/10.1177/1049732316665348

Tippens, J. A. (2020a). Generational perceptions of support among Congolese refugees in urban Tanzania. Global Social Welfare : Research, Policy \& Practice, 7(1), 69-80. https://doi.org/10.1007/s40609-019-00155-2

Tippens, J. A. (2020b). Urban Congolese refugees' social capital and community resilience during a period of political violence in Kenya: A qualitative study. Journal of Immigrant \& Refugee Studies, 18(1), 42-59. https://doi.org/10.1080/1 $\underline{5562948.2019 .1569744}$

Tol, W. A., Kohrt, B. A., Jordans, M. J., Thapa, S. B., Pettigrew, J., Upadhaya, N., \& de Jong, J. T. (2010). Political violence and mental health: a multi-disciplinary review of the literature on Nepal. Social Science \& Medicine, 70(1), 35-44. 
Turner, T. (2007). The Congo wars: Conflict, myth and reality. Zed Books. https://doi. org/10.5040/9781350223011

United Nations Refugee Agency. (2014). Global strategy for public health. https:// www.unhcr.org/en-us/protection/health/530f12d26/global-strategy-publichealth-unhcr-strategy-2014-2018-public-health-hiv.html

United Nations Refugee Agency. (2020a). DR Congo emergency. https://www.unhcr. org/en-us/dr-congo-emergency.html

United Nations Refugee Agency. (2020b). Figures at a glance. https://www.unhcr. org/en-us/figures-at-a-glance.htm

United Nations Refugee Agency. (n.d.a). Glossary. https://reporting.unhcr.org/ glossary

United Nations Refugee Agency. (n.d.b). Operations portal-Refugee situations: DRC situation. https://data2.unhcr.org/en/situations/ drc\# ga=2.191323946.1476055947.1602108859-2100899321.1599612520

United Nations Refugee Agency, Kenya. (2020). Kenya: Urban areas. https://www. unhcr.org/ke/urban-areas

United Nations Refugee Agency, Kenya. (2021). Kenya: Registered refugees and asylum seekers as of 28 February 2021. https://www.unhcr.org/ke/wp-content/ uploads/sites/2/2020/08/Kenya-Infographics-28-February-2021.pdf

Virgincar, A., Doherty, S., \& Siriwardhana, C. (2016). The impact of forced migration on the mental health of the elderly: A scoping review. International Psychogeriatrics, 28(6), 889.

Valdez, E. S., Valdez, L. A., \& Sabo, S. (2015). structural vulnerability among migrating women and children fleeing Central America and Mexico: the public health impact of "humanitarian parole". Frontiers in Public Health, 3, 163. 